\title{
Trying to Reconcile Genetic Findings with Resistance to Lymphocyte Apoptosis in Crohn's Disease Pathogenesis
}

\author{
Miquel Sans \\ Department of Gastroenterology, Hospital Clínic i Provincial/IDIBAPS, CIBER EHD, Barcelona, Spain
}

In this issue of Digestion, Zimmer et al. report on a study of 149 European Crohn's disease (CD) patients and 478 healthy controls. They found that there is a genderspecific, inverse relationship between the low-apoptotic p53 SNP72 CC genotype and CD as well as an interaction between the p53 SNP72 CC and the mdm2 SNP309 TT genotypes. Although it reached statistical significance in the study by Zimmer et al., from a biological point of view the association of CD to the p53 SNP72 CC genotype, which would reduce lymphocyte apoptosis, is difficult to reconcile with our present understanding of CD pathogenesis.

In the last decade the resistance of lymphocytes to undergo apoptosis has been considered a hallmark of $\mathrm{CD}$ pathogenesis. The initial investigations undertaken by Ina et al. [1] and Itoh et al. [2] in Cleveland, elegantly demonstrated that lymphocytes from CD but not ulcerative colitis patients are highly resistant to both fas-mediated and IL-2-deprivation-induced apoptosis. Apoptosis is regulated by two major intracellular pathways. In the extrinsic pathway, activation of Fas and other membrane receptors results in activation of caspase 8 , which activates the effector caspase 3 , leading to DNA cleavage and cell membrane changes, ultimately causing programmed cell death. In the intrinsic pathway caspase 3 is activated by a complex of proteins, including caspase 9, APAF-1, and cytochrome $\mathrm{C}$, known as the apoptosome. This path- way is activated by leakage of cytochrome $\mathrm{C}$ from the mitochondria which, in turn, is regulated by the Bcl-2 family of proteins. The apoptosis defect in mucosal $\mathrm{T}$ cells in $\mathrm{CD}$ has been attributed to an imbalance between two mitochondrial proteins, the anti-apoptotic $\mathrm{Bcl}-2$ and the pro-apoptotic Bax $[1,2]$.

The notion that restoration of apoptosis in the T-mucosal T-cell compartment is an important contributing factor for successful treatment of CD has also been widely accepted based on the fact that the most efficacious drugs for $\mathrm{CD}$, including sulfasalazine, steroids, azathioprine, infliximab and adalimumab, are strong inducers of lamina propria T-cell apoptosis [3]. Moreover, the lack of efficacy of etanercept in the treatment of CD was immediately claimed to be caused by its failure to induce apoptosis of these cells [4]. More recently, however, this concept has been challenged by certolizumab pegol, an anti-TNF- $\alpha$ molecule efficacious in inducing and maintaining remission in $\mathrm{CD}$ patients, in spite of its inability to cause apoptosis on TNF- $\alpha$-expressing cells due to the lack of an Fc fragment.

The field of inflammatory bowel disease genetics has experienced an explosion of interest in the last 3 years. The arrival of the genome-wide association studies (GWAS) allowed researchers to undertake unbiased, comprehensive investigations of the genetic factors associated with CD. As a result of the published GWAS and

\section{KARGER}

Fax +4161306 1234 E-Mail karger@karger.ch www.karger.com
(C) 2010 S. Karger AG, Base

$0012-2823 / 10 / 0814-0244 \$ 26.00 / 0$

Accessible online at:

www.karger.com/dig
Miquel Sans, $\mathrm{MD}, \mathrm{PhD}$

Department of Gastroenterology, Hospital Clínic i Provincial/IDIBAPS

170 Villarroel

ES-08036 Barcelona (Spain)

Tel. +3493227 5418, Fax +3493227 9387, E-Mail msans@ @linic.ub.es 
subsequent meta-analysis, more than 30 susceptibility loci for CD have been described to date [5]. Of note, the two genetic factors studied by Zimmer et al., the p53 SNP72 and the mdm2 SNP309, were not found to be associated with CD in the GWAS studies. However, it must be taken into account that in the study by Zimmer et al. the association was only observed in males, whereas the GWAS did not include gender sub-analyses.

Taking all the above into account, we cannot rule out the possibility that the inverse relationship between the p53 SNP72 CC genotype and CD described by Zimmer et al. in this issue of Digestion were 'false-positive'. The relatively low number of cases included in the study (the finding is only based on $71 \mathrm{CD}$ males) might have led to a type-1 error, a possibility that is very appropriately acknowledged by the authors in their discussion. In any case, and due to the key role of p53 and $\mathrm{mdm} 2$ on cell cycle and apoptosis, more and larger studies are warranted to try to replicate the results obtained by Zimmer et al.

\section{References}

1 Ina K, Itoh J, Fukushima K, et al: Resistance of Crohn's disease T cells to multiple apoptotic signals is associated with a Bcl-2/Bax mucosal imbalance. J Immunol 1999;163: 1081-1090.

2 Itoh J, de La Motte C, Strong SA, et al: Decreased Bax expression by mucosal $\mathrm{T}$ cells favours resistance to apoptosis in Crohn's disease. Gut 2001;49:35-41.
- 3 ten Hove T, van Montfrans C, Peppelenbosch MP, et al: Infliximab treatment induces apoptosis of lamina propria $\mathrm{T}$ lymphocytes in Crohn's disease. Gut 2002;50: 206-211.

-4 Sandborn WJ, Hanauer SB, Katz S, et al: Etanercept for active Crohn's disease: a randomized, double-blind, placebo-controlled trial. Gastroenterology 2001;121:10881094.
5 Barrett JC, Hansou S, Nicolae DL, et al: Genome-wide association defines more than 30 distinct susceptibility loci for Crohn's disease. Nat Genet 2008;40:955-962. 